\title{
Use of Vascularized Periosteal Flaps in Upper Extremity Pathology
}

\section{Uso de Colgajos Vascularizados Periósticos en la Patología de la Extremidad Superior}

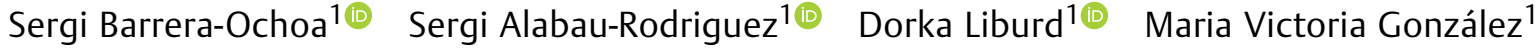 \\ Xavier Mir-Bulló ${ }^{1}$ Francisco Soldado 2,3 (1)
}

1 icatMA Hand and Microsurgery Unit, ICATME, Hospital Universitari

Address for correspondence Sergi Alabau Rodríguez, MD, icatMA Quiron-Dexeus, Barcelona, Spain

2 Pediatric Orthopedics Department, Hospital Universitari Vall d'Hebron, Barcelona, Spain

3 Pediatric Surgery, Hand and Microsurgery, Hospital Vithas San Jose, Hand and Microsurgery Unit, ICATME, Hospital Universitari QuironDexeus, Carrer Sabino de Arana, 5-19, Barcelona 08028, Spain (e-mail: dr.sergialabau@gmail.com).

Vitoria, Spain

Rev Iberam Cir Mano 2020;48:42-52.

\begin{abstract}
Keywords

- vascularized periosteal flap

- pediculated flap

- periosteum

- upper extremity

- pseudoarthrosis

- bone defect
\end{abstract}

\section{Resumen}

Massive bone defects represent a challenge in orthopedics. The structural and biological contribution of vascularized bone flaps has significantly improved their treatment. Similarly, free vascularized periosteal flaps (VPF) have been used to treat bone defects in children, with higher flexibility, adaptability to the recipient's bed and good osteogenic and osteoinductive capacity. However, these are complex techniques related to donor area morbidity. We have started anatomical and clinical studies on the application of pediculated VPF in recalcitrant massive defects to reduce this morbidity. This article summarizes the fundamental aspects of the surgical technique, the main anatomical findings from cadaveric dissections and the applicability of pediculated VPF to treat biologically unfavorable bone defects at the upper limb. The authors review the vascularized humeral periosteal flap (VHPF), the dorso-ulnar and volar-radial forearm periosteal flaps and the vascularized first metacarpal periosteal flap, all described in previous papers. As a novelty, the dorsal wrist and hand VPF (4-5 radial periosteal flap and dorsum of the second metacarpal bone periosteal flap) are presented. In addition, clinical cases with recent VPF applications in common upper limb conditions are described.

Los defectos óseos masivos representan un gran reto en cirugía ortopédica. El aporte estructural y biológico mediante colgajos óseos vascularizados libres ha mejorado significativamente su tratamiento. Asimismo, se han utilizado colgajos vascularizados libres provenientes del periostio (CVP) de los niños para tratar defectos óseos, permitiendo más flexibilidad, adaptabilidad al lecho receptor, así cómo mayor potencial osteogénico y osteoinductivo. Sin embargo, se trata de técnicas complejas que pueden generar morbilidad en la zona donante. Para solventarlo, hemos iniciamos el estudio anatómico y la aplicación clínica de CVP para defectos masivos recalcitrantes received

March 7, 2020

accepted

March 16, 2020
DOI https://doi.org/

$10.1055 / \mathrm{s}-0040-1712095$. ISSN 1698-8396.
Copyright $\odot 2020$ Thieme Revinter

Publicações Ltda, Rio de Janeiro, Brazil
License terms

(c) $(1) \$$ 


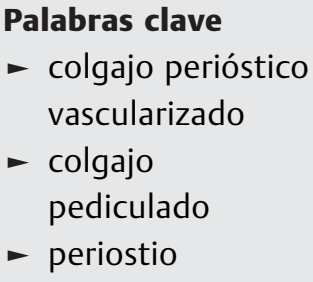

con un diseño pediculado. En este artículo se resumen los aspectos fundamentales de la técnica quirúrgica, la anatomía mediante disecciones cadavéricas, así cómo la aplicabilidad de los CVP pediculados para tratar patología ósea biológicamente desfavorable de la extremidad superior. Se resumen el CVP humeral, los CVP de antebrazo dorsoulnar y volar-radial, así cómo el CVP de primer metacarpiano, todos ya descritos en artículos previos. Como novedad, se describen los CVP del dorso de la muñeca y la mano (CVP 4-5 Radial y CVP del dorso del $2^{\circ}$ metacarpiano). Asimismo, se muestran casos clínicos novedosos sobre la utilización de los CVP en las patologías habituales de la extremidad superior.

\section{Introduction}

Recalcitrant pseudoarthrosis, avascular necrosis and massive bone defects represent great orthopedic surgery challenges due to their complex biological context. Even though rare situations are considered, ${ }^{1}$ especially in pediatric patients, these injuries usually affect individuals presenting large bone defects of traumatic, iatrogenic or congenital origin which are reconstructed with non-vascularized bone grafts lacking angiogenic supply. In addition, some bone defects derive from unfavorable contexts, like long-term infections or bone tumors. ${ }^{2-7}$

Optimal treatment for these cases requires precise and individualized planning to provide both angiogenic and osteogenic potential. ${ }^{8}$ Various meta-analyzes have shown that, in these unfavorable situations, vascularized bone flaps offer better outcomes compared to non-vascularized flaps, with consolidation rates of up to $80-100 \%$ for corticoperiosteal flaps ${ }^{9}$ and medial femoral condyle osteochondral flaps. However, these flaps are complex to generate, require great surgical skill for anastomoses, and are often associated with high donor area morbidity.

As such, vascularized periosteal flaps (VPF) have been used to treat children with lower limb defects in biologically unfavorable conditions. ${ }^{2,10-13}$ These periosteal flaps are flexible and highly adaptable to the receptor bed. Furthermore, they are not related to donor area morbidity. Fibular, tibial and even first metatarsal VPFs have been described, and reportedly have excellent consolidation and revascularization rates. ${ }^{4,13}$ This is due to the rich periosteal vascularization, which allows flap survival, and to the enormous osteogenic potential of the stem cells from the periosteum cambium layer. These progenitor cells, in contrast to what happens during fracture healing, become osteoblasts, increasing the bone axis diameter through intramembranous ossification. In addition, the periosteum promotes and accelerates both autologous and heterologous bone integration and revitalization. ${ }^{14}$ In heterologous bone, they also result in the acquisition of histological and biomechanical features which are similar to those presented by the host bone. The reconstruction technique tries to wrap the defect or segment to be reconstructed with the VPF to achieve its fast integration. ${ }^{15}$

However, all these flaps are free and, as a disadvantage, require a double surgical field and a double surgical team; consequently, they present a high degree of technical complexity that results in low reproducibility and long surgical time for those with little training in microsurgery. As such, in recent years, we started the study and clinical application of pediculated VPFs in upper extremity defects to obtain a surgical technique complying with the premises of technical ease, graft adaptability, osteoinductive capacity and fast integration, as well as low donor area morbidity. ${ }^{16-19}$ Consolidation and revascularization of the bone defect were obtained in all cases, with no complications. ${ }^{17}$

This paper summarizes and details the fundamental aspects of the surgical technique, the regional anatomy studied through cadaveric dissections, and the indications for pediculated VPFs in upper limb conditions.

\section{Periosteal Humeral Vascularized Flap}

\section{Anatomy}

The lateral humeral VPF anatomy is based on posterior collateral radial vessels (VRCP), especially their periosteal branches. VRCPs run over the posterior aspect of the lateral intermuscular septum, originating anterior and posterior periosteal branches transverse to the distal lateral humerus. There are four to seven anterior periosteal branches and three to seven posterior periosteal branches ( - Fig. 1). Distally, VRCPs join the interosseous recurrent artery and the radial recurrent artery to create a vascular network over the lateral condyle. ${ }^{18}$

\section{Clinical Usefulness}

This is a viable surgical option for conditions such as lateral humeral condylar and distal humeral diaphyseal pseudoarthrosis. The reported average incidence of pseudoarthrosis after distal humerus fractures ranges from $2 \%$ to $10 \% .^{7,18,20}$ In children, humeral lateral condyle (CLH) fractures are the second most common elbow fracture, and nonunion is a relatively common complication, ${ }^{15}$ resulting in a high risk of bone necrosis and chronic elbow stiffness. ${ }^{15,20}$ Open reduction and internal fixation with or without autologous or heterologous bone graft remains the most frequent treatment method. ${ }^{16,21}$ The complexity of treating these lesions is usually increased by their association with poor bone quality, small, difficult to stabilize bone fragments, and previous surgeries and approaches that compromise bone consolidation and viability.

\section{Clinical Case}

We present the case of a 2-year-old boy with pseudoarthrosis of the left CLH after an unsuccessful previous treatment. The initial 
treatment consisted of percutaneous fixation with a compression cannulated screw and it was performed four months earlier. Follow-up radiographs showed peri-implant loosening. ${ }^{18}$

A lateral longitudinal incision was made and the lateral humeral septum and VRCP were identified. The brachioradialis/brachialis muscle fibers were separated anteriorly, whereas triceps muscle fibers were separated posteriorly. The radial nerve was protected. A $3.5 \times 2 \mathrm{~cm}$ vascularized humeral VPF was elevated $2 \mathrm{~cm}$ proximal to the pseudoarthrosis. VRCP were ligated proximally, while the flap was pediculated in retrograde flow. The pseudoarthrosis was identified by fluoroscopy and debrided up to $2 \mathrm{~mm}$ deep at the lateral supracondylar margin level. The previous screw was not removed. The VPF was turned distally with the cambium layer oriented towards the pseudoarthrosis and stabilized by sutures at each corner of the flap. A complete posterior brachial splint was used for three weeks after surgery. ${ }^{19}$

Radiographs at 3 weeks revealed an initial ossified callus; at 6 weeks, images showed a complete ossified bone callus joining the pseudoarthrosis site. Four months after surgery, consolidation was almost complete and the peri-implant osteolysis disappeared (-Fig. 2). The active full range of motion of the elbow was regained 3 months after surgery. ${ }^{18}$

\section{Periosteal Vascularized Flaps from the Forearm}

\section{Anatomy}

The most versatile and useful VPFs from the forearm are the dorso-ulnar VPF based on posterior interosseous vessels $(\mathrm{VIP})^{19}$ (- Fig. 3) and the volar-radial VPF based on anterior interosseous vessels (VIA). ${ }^{16}$ (- Fig. 4).

VIPs and their branches in the ulnar periosteum are exposed between the extensor carpi ulnaris (ECU) and extensor digiti minimi (EDM) muscles (-Fig. 5). VIPs emerge at the posterior compartment below the supinator muscles; VIPs cutaneous and muscular branches are identified along their path. These vessels originate periosteal branches arising from both the medial (60\%) and lateral (40\%) sides and extend themselves transversely through the dorsal ulnar periosteum. The periosteal branches are distributed mainly along a distal cubital length of $15 \mathrm{~cm}$, with an average distance of $1 \mathrm{~cm}$ between branches. The flap has an average of 12.8 periosteal branches. The average size of a dorso-ulnar VPF is $20.4 \mathrm{~cm}^{2,19}$

The volar-radial VPF is based on VIAs from the anterior compartment, between the brachioradialis and the flexor carpi radialis (FCR), including the deep muscular fascia from ulnar to radial up to the intermuscular FCR septum, where the perforating arteries are identified. ${ }^{16}$ This flap presents, on average, 16.2 periosteal branches, with 7.7 septocutaneous branches and 18.1 muscle branches. Of these, 7.5 branches provide vascularization to the pronator quadratus and 11.2 for the flexor digitorum profundus (FDP). The average size of a volar-radial VPF is $41.3 \mathrm{~cm} .^{2,16}$

\section{Clinical Usefulness}

These flaps can be used interchangeably for radius and ulna pseudoarthrosis depending on the receiving area, along their

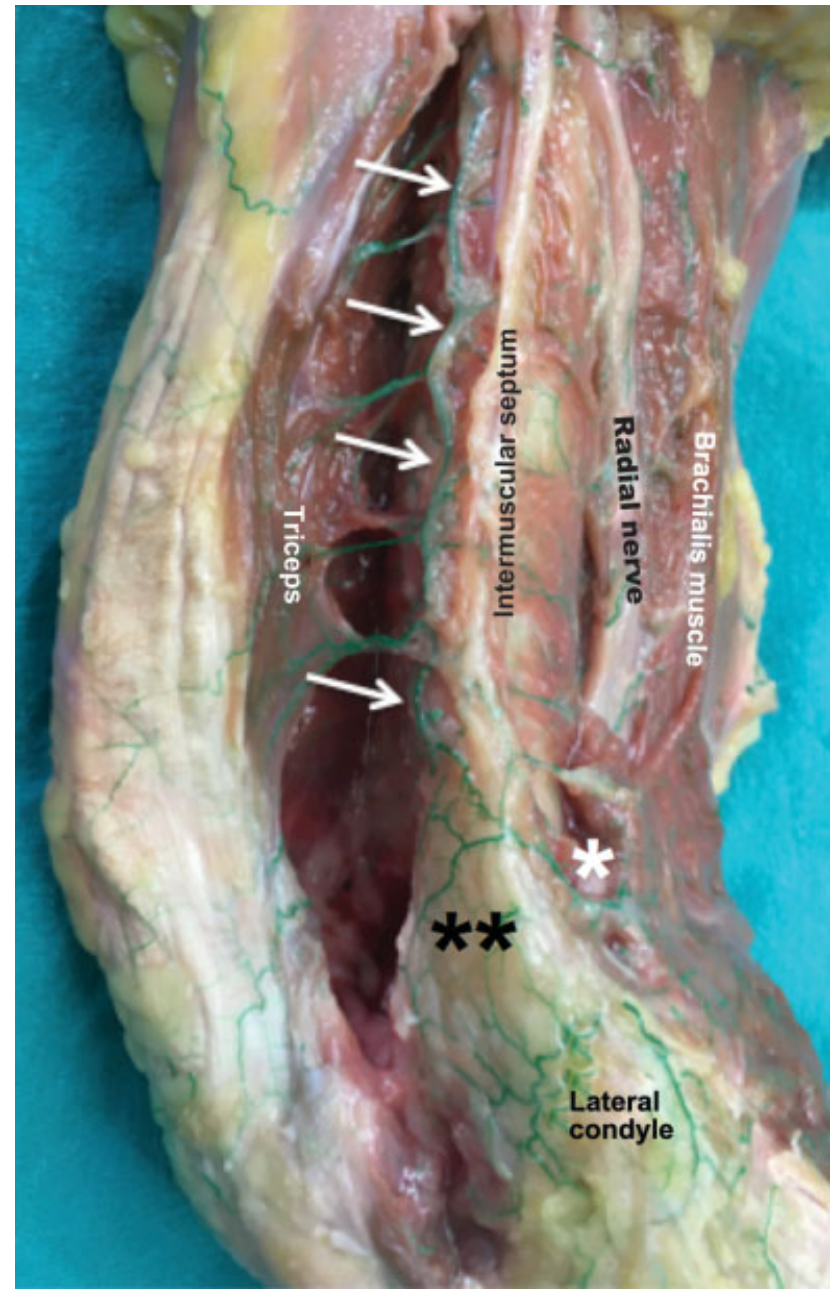

Fig. 1 Lateral view of the elbow; anatomical dissection showing the posterior radial collateral artery (white arrows), located on the posterior aspect of the intermuscular septum, giving origin to anterior and posterior periosteal branches. Distally, it joins the radial recurrent artery (anterior, ${ }^{*}$ ) and the interosseous recurrent artery (posterior, $\left.{ }^{* *}\right)$, creating a vascular network over the lateral condyle.

whole length, from wrist to elbow, in congenital forearm abnormalities and in bone defects or pseudoarthrosis of the wrist (carpus) and fingers (metacarpal bones and proximal phalanges). ${ }^{16,19}$

Forearm pseudoarthroses are rare, but difficult to treat, with a challenging surgical approach (-Fig. 6). Multiple factors have been associated to this condition, including fracture location and complexity, patient characteristics and the surgical technique. Treatment for forearm diaphyseal fractures is unique regarding other types of diaphyseal pseudoarthrosis due to the intimate relationship between radius and ulna and their reciprocal movement. There is a wide range of surgical techniques and the optimal choice remains controversial. Forearm fracture reduction and fixation with compressive plates and screws has proven to be an effective procedure in adults. Complications and pseudoarthrosis rates are low, reportedly below $5 \%$ in large series. ${ }^{15,16}$ Forearm pseudoarthrosis is severely disabling because the dysfunction extends from the elbow to the wrist. ${ }^{21-24}$ 


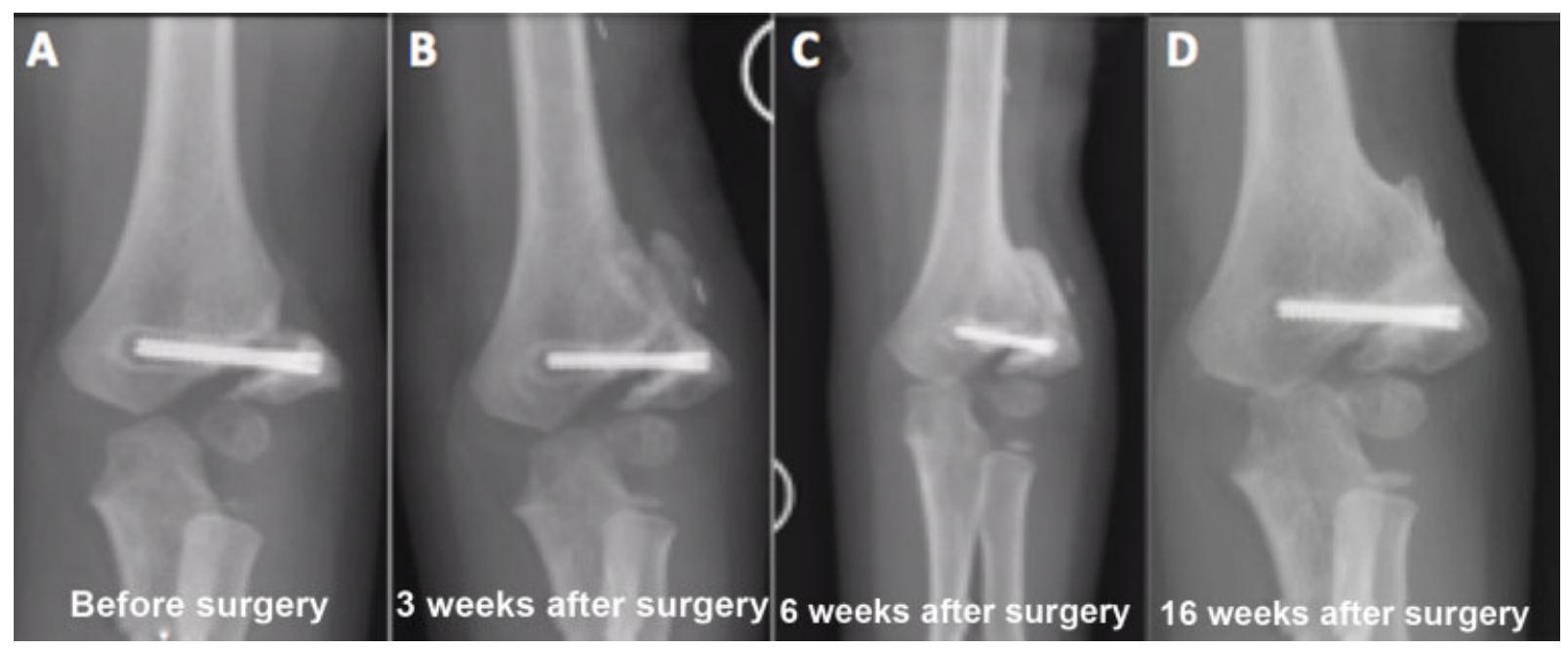

Fig. 2 A, Preoperative radiography showing non-persistent union of the lateral condyle of the elbow and conical screw loosening. B, Initial ossified periosteal callus 3 weeks after surgery. C, Advanced, ossified periosteal callus joining the pseudoarthrosis site 6 weeks after surgery. D, Sixteen weeks later, the pseudoarthrosis resolved almost completely despite the lateral superficial placement of the vascularized humeral periosteal flap. The peri-implant osteolysis region was also filled with bone tissue.

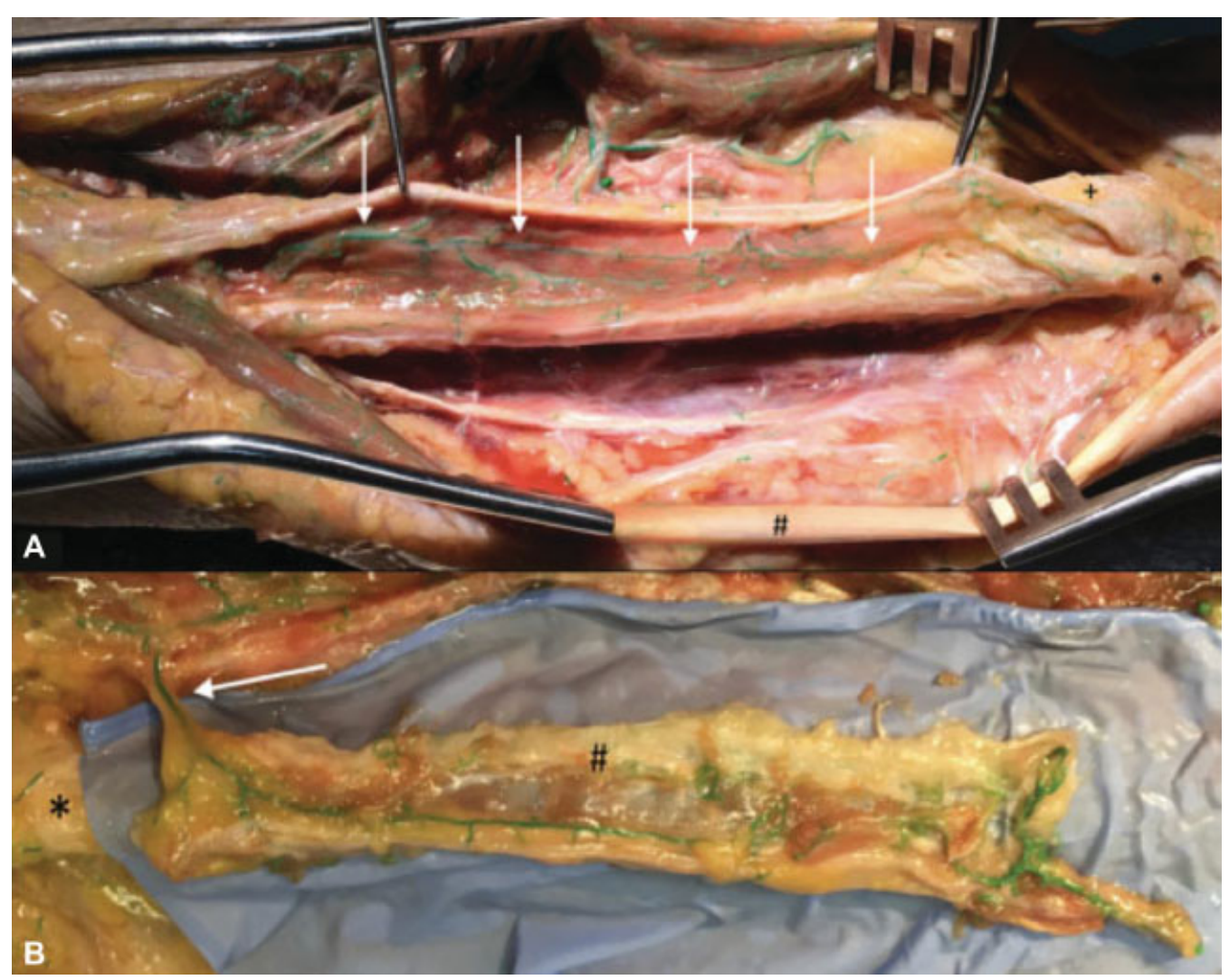

Fig. 3 Dorso-ulnar periosteal vascularized flap (VPF) (posterior interosseous artery vascular axis). A, +, ulnar dome; *, ulnar styloid; \#, extensor carpi ulnaris; white arrows - periosteal branches of the posterior interosseous artery. B, Example of a dorso-ulnar VPF dissection based on the posterior interosseous artery (white arrow), showing its length and width.

\section{Clinical Case}

Six-year-old girl with a history of open diaphyseal radius fracture (Gustilo I) treated by internal fixation with an elastic intramedullary pin. Since the patient developed an atrophic pseudoarthrosis, a VIP-based VPF was performed without osteosynthesis material replacement or bone grafting in the pseudoarthrotic focus, achieving complete consolidation in 6 months.

\section{Clinical Case}

Male, 52-year-old patient with recalcitrant olecranon pseudoarthrosis. The patient had undergone three previous 


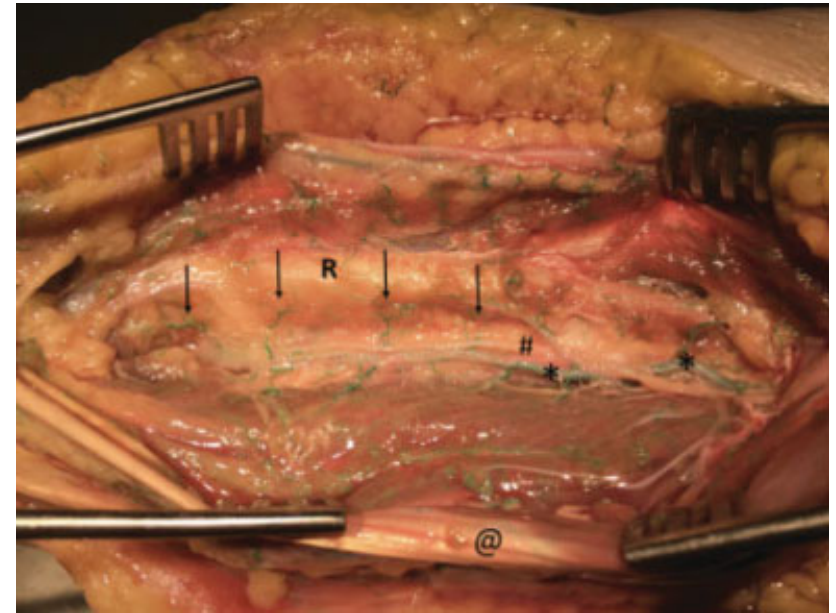

Fig. 4 Anterior compartment of the forearm. *, Anterior interosseous artery and its periosteal branches; @, flexor digitorum superficialis; R, radius; \#, anterior interosseous nerve in its path radial to the anterior interosseous artery.

surgeries after non-consolidation of an olecranon osteotomy as an approach to a comminuted supraintercondylar fracture. The first surgery consisted in osteosynthesis material replacement and heterologous corticocancellous bone graft, whereas the second surgery used an autologous iliac crest graft. In this case, the osteosynthesis material was replaced and an anterograde dorso-ulnar VPF was added as a biologi- cal factor. Pseudoarthrosis consolidation was achieved in 6 months (-Fig. 7).

\section{Clinical Case}

Male, 36-year-old patient with carpometacarpal pseudoarthrosis between the base of the $4^{\text {th }}-5^{\text {th }}$ metacarpal (MTC) bones and the hook of the hamate bone. The patient had undergone four surgeries after a failed attempt of carpalMTC arthrodesis for a previous dislocation fracture. Prior surgeries for pseudoarthrosis treatment included a partial osteosynthesis material removal and an olecranon autologous cortical cancellous bone grafting. In this case, the osteosynthesis material was not replaced and a retrograde dorso-ulnar VPF was added as a biological factor (-Fig. 8). Pseudoarthrosis consolidation was achieved in 6 months (-Fig. 9).

\section{Periosteal Vascularized Flaps for Dorsal Wrist and Hand}

\section{Anatomy}

VPFs for dorsal wrist and hand are based on the vascular branches of the dorsal carpal branch of the radial artery emerging at the radial fossa. The most versatile VPF in this region is made with back of the first metacarpal bone. This is an antegrade pedicle flap with an average size of $4 \times 1.2 \mathrm{~cm}$, designed on the distal region of the dorsal first metacarpal

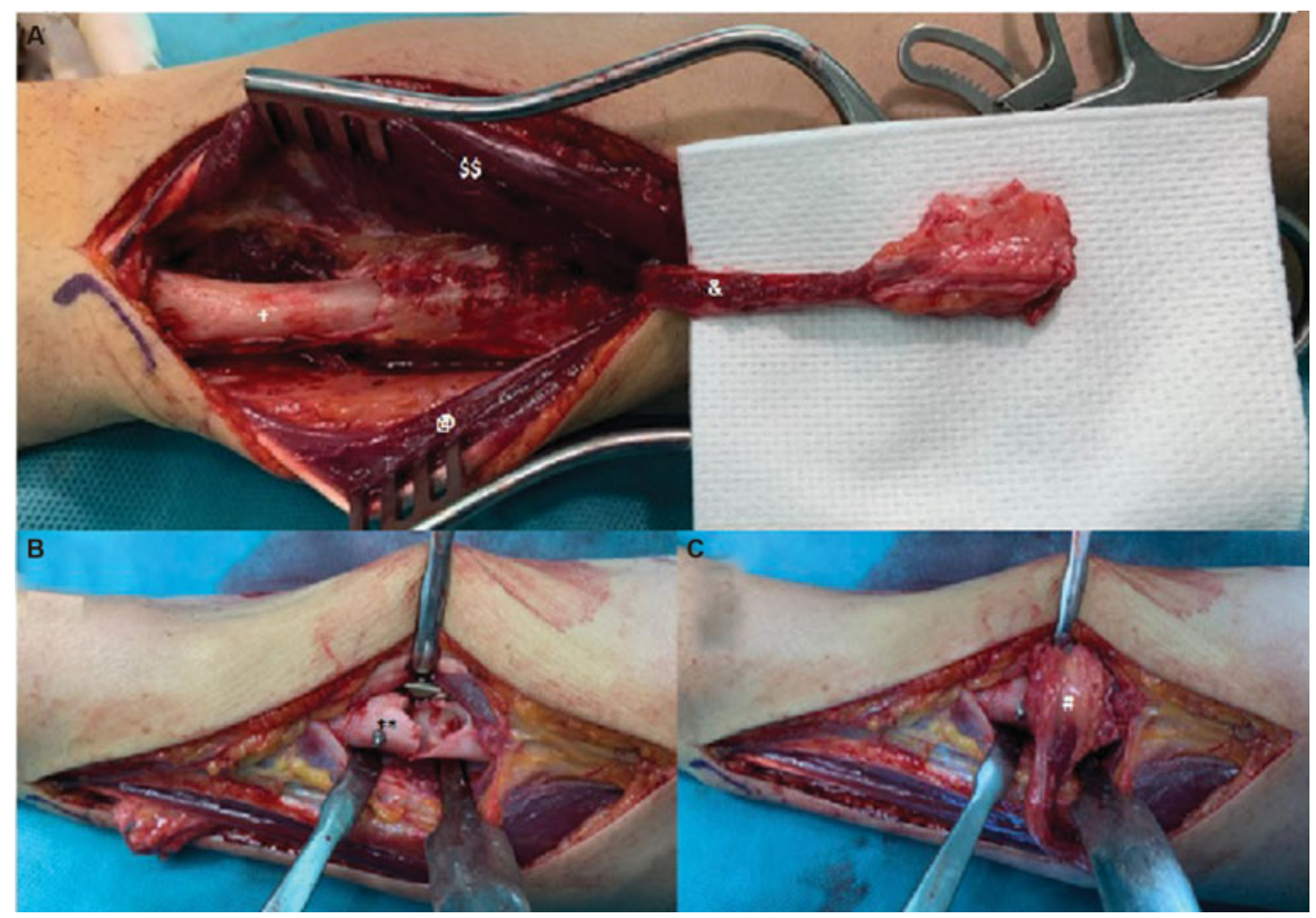

Fig. 5 A, Dorsal-ulnar vascularized periosteal flap (VPF) elevation at the posterior compartment of the forearm. +, Ulnar diaphysis; @, extensor carpi ulnaris; \$ , extensor digiti minimi; \&, length of the pedicle based on the posterior interosseous artery. B, ${ }^{* *}$, Pseudoarthrosis focus debridement at the level of the radial shaft. C, \#, VPF implantation in the receptor bed in contact with the cambium layer. 


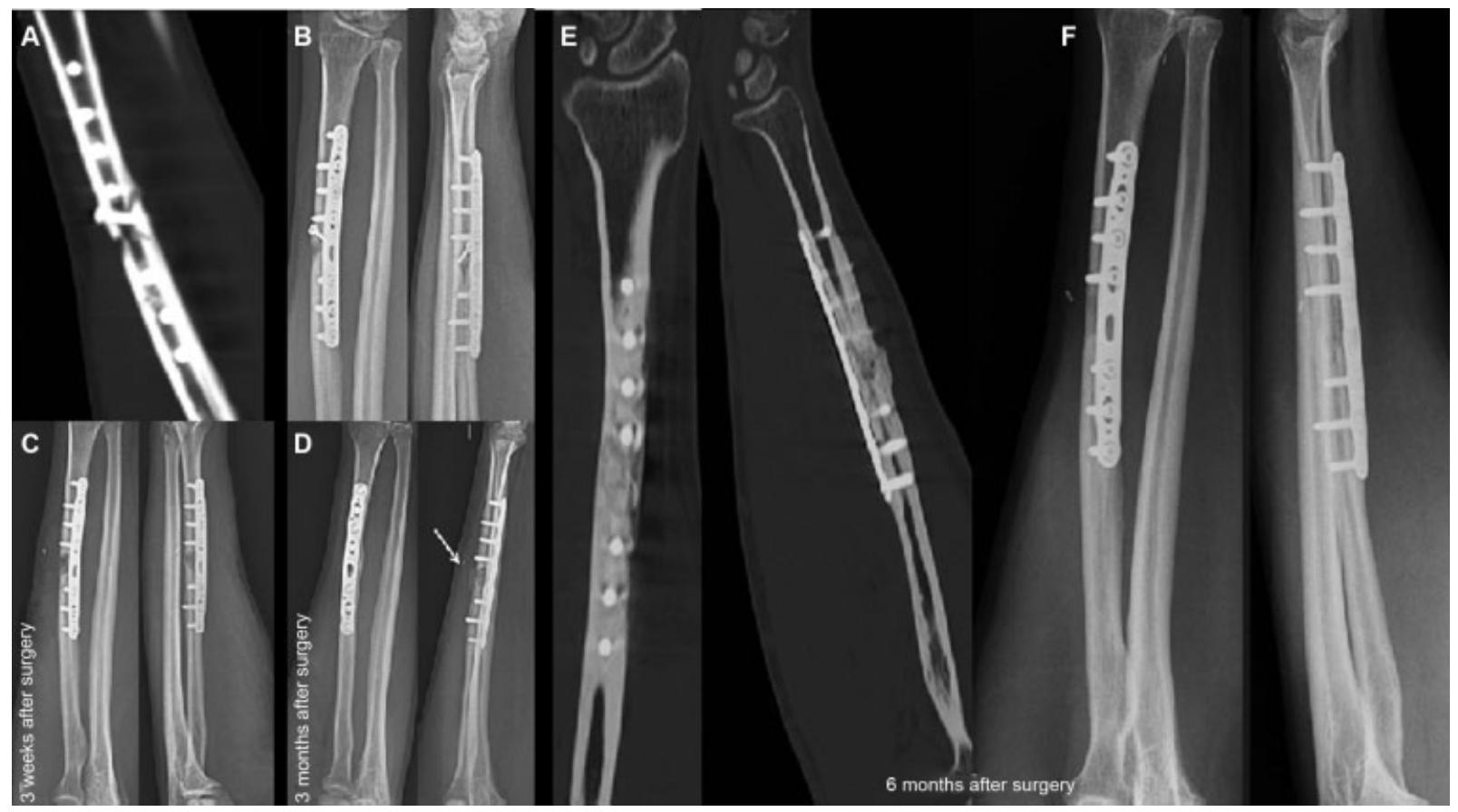

Fig. 6 Preoperative imaging studies. A, Computed tomography (CT) scan of the left radius showing a fracture at the middle third of the radial diaphysis surgically treated with plate and screws, resulting in good fragments approximation. The cortical surfaces are separated by 3 mm, and there are signs of atrophic pseudoarthrosis at the screw level in the dorsal aspect of the fracture. B, Anteroposterior and Lateral postoperative radiographs of left forearm. C, Periosteal consolidation 6 weeks after surgery. D, Higher bone mineral density within the pseudoarthrosis focus and periosteal consolidation signs (arrow) 3 months after surgery. E, postoperative CT scan at 6 months follow-up showing bone consolidation. F, postoperative forearm radiographs showing bone consolidation at 6 months.

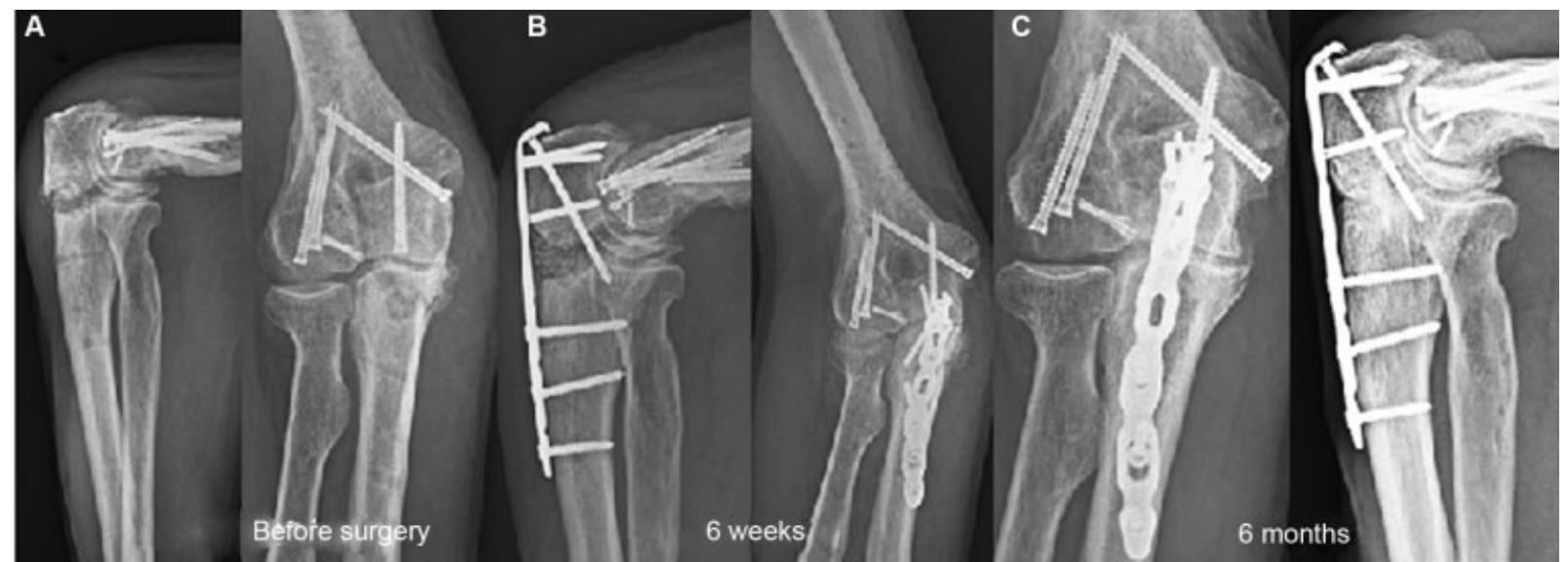

Fig. 7 Anteroposterior (AP) and lateral radiographies of the right elbow. A, Absence of olecranon osteotomy consolidation after a supraintercondylar fracture of the right humerus. B, Stabilization with an olecranon anatomical plate, $5 \mathrm{ml}$ of cortical-cancellous bonde allograft + antegrade dorso-ulnar vascularized periosteal flap. (C) Increased bone density at the medial area following progressive consolidation, 6 months after surgery.

bone, between the abductor pollicis longus (APL) and extensor pollicis brevis tendon (EPB) tendons. It has a $5.2 \mathrm{~cm}$-long pedicle $^{17,25}$ and, on average, it includes 12 periosteal branches ${ }^{17,25}$ from the vascular axis of the first dorsal metacarpal artery (PDMA)( - Fig. 10).

A VPF from the base of the second metacarpal bone is another pedicle flap based on the dorsal carpal branch of the radial artery. Four independent intermetacarpal branches emerge from this carpal branch for each intermetacarpal space. On the back of each metacarpal bone, periosteal branches from anastomoses between these con- tiguous intermetacarpal arteries can be identified. The second metacarpal bone flap can be anterograde or retrograde depending on the location and features of the defect to be treated, obtaining a pedicle with an average length of $4.2 \mathrm{~cm}$ (-Fig. 11).

The 4-5 radial VPF is another pediculated flap from the back of the wrist with wide applicability. Its vascular axis is based on the fifth extensor compartment (5th RCT) artery, a direct branch from the anastomotic arch between the anterior interosseous artery and the posterior interosseous artery. It has a mean size of $3.7 \mathrm{~cm}^{2}$ and, on average, it consists 


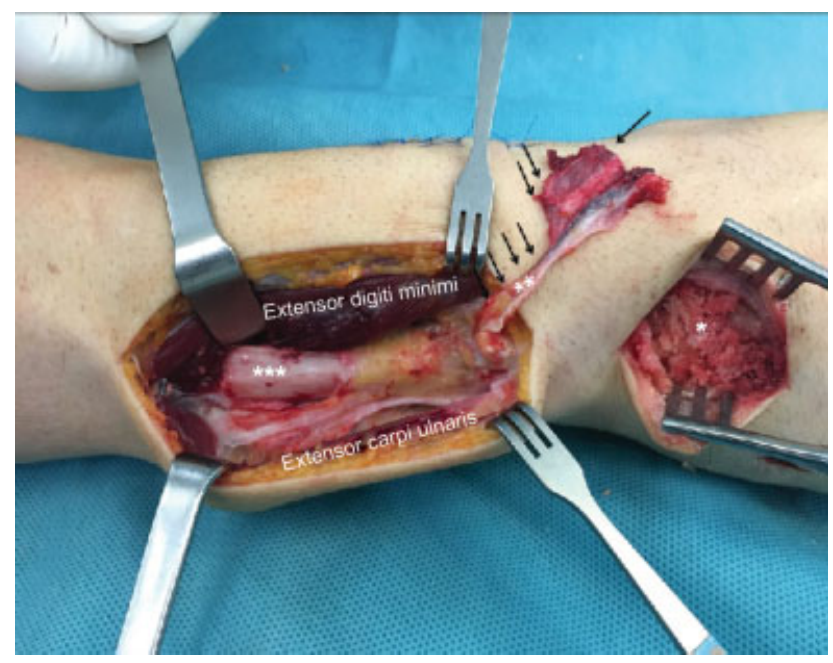

Fig. 8 Dorsal forearm region. Dorso-ulnar vascularized periosteal flap (posterior interosseous artery vascular axis). ${ }^{* * *}$, Ulnar diaphysis; ${ }^{* *}$, pediculated periosteal flap from the posterior interosseous artery, retrograde elevation; *, autologous olecranon cancellous graft. Flap length and width are shown (arrows). of four periosteal branches (range, 3 to 7 ) with a $4.4 \mathrm{~cm}$-long pedicle (-Fig. 12).

\section{Clinical Usefulness}

The first MTC VPF is a very versatile flap with abundant and consistent vascularization. It has an optimal size for small defects of up to $4 \mathrm{~cm}^{2}$. The length of its pedicle $(5.2 \mathrm{~cm})$ allows it to be used both for scaphoid pseudoarthrosis and/or avascular necrosis either by a volar and dorsal approach ${ }^{17-25}$. It can also be used for semilunar necrosis or Kienböck disease through a dorsal approach, although 4-5 radial VPFs are often preferred in such cases.

Since it can be designed using a retrograde or antegrade flow, the periosteal flap from the base of the second MTC bone also allows multiple therapeutic indications. Flaps with an antegrade design can be used to treat scaphoid pseudoarthrosis through a dorsal approach or contiguous MTC bones pseudoarthrosis. Those with a retrograde flow can be used to treat MTC pseudoarthrosis or even more distal defects, such as proximal phalangeal pseudoarthrosis of the second and third fingers.

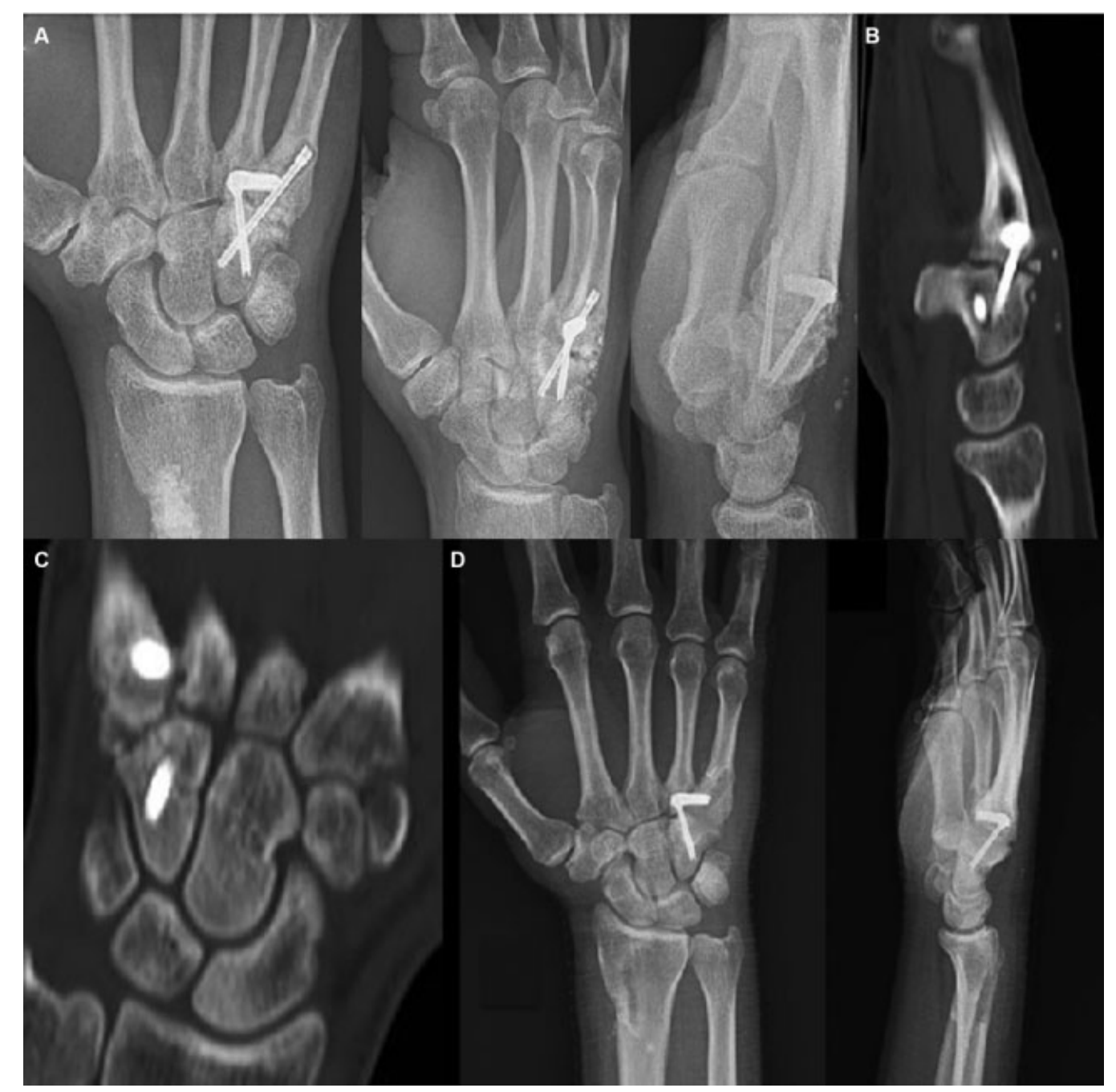

Fig. 9 Carpometacarpal pseudoarthrosis between the base of the $4^{\text {th }}$ and $5^{\text {th }}$ metacarpal bone, 12 months of evolution. (A, B and C) Radiographic views and computed tomography (CT) scans of the wrist showing persistence of the pseudoarthrosis focus after the last surgical intervention. (D) Anteroposterior and lateral radiographies of the wrist showing complete consolidation after the placement of a dorso-ulnar vascularized periosteal flap. 


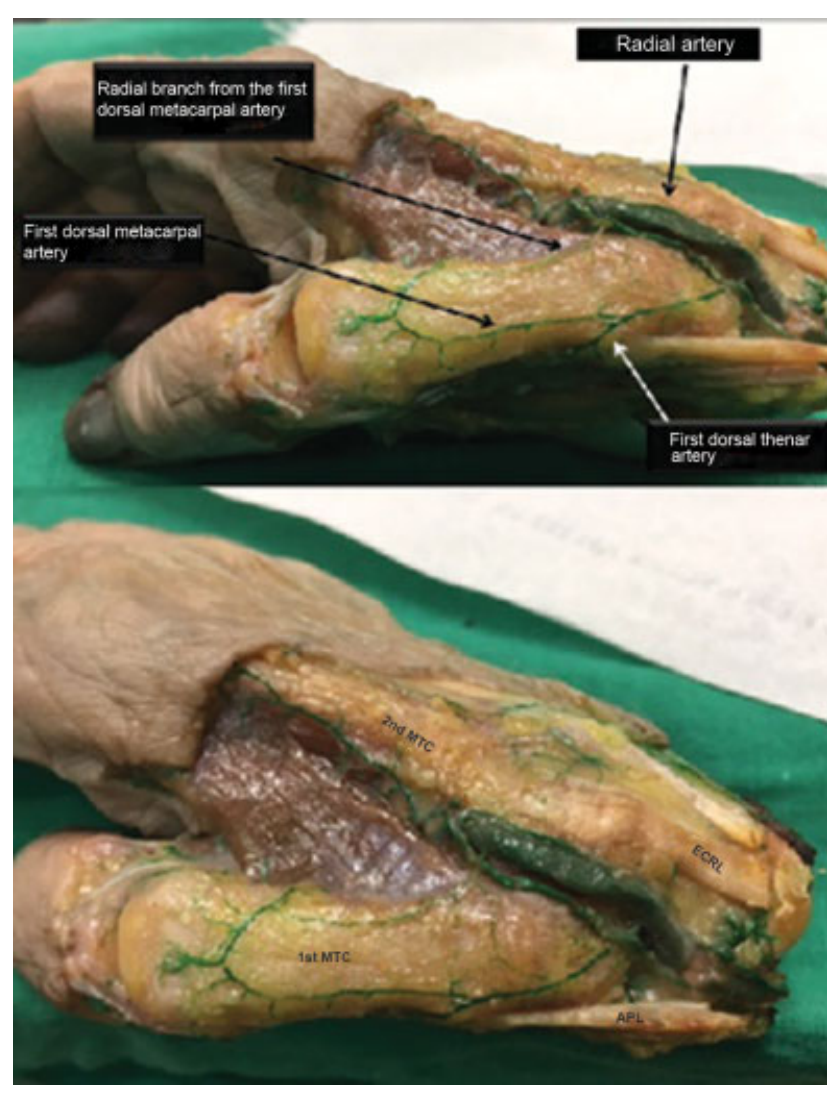

Fig. 10 Vascularized periosteal flap of the dorsum of the first metacarpal bone based on periosteal branches from the first metacarpal artery, a branch from the radial artery at the radial fossa level. $2^{\text {nd }}$ MTC, second metacarpal bone; ECRL, extensor carpi radialis longus; $1^{\text {st }}$ MTC, first metacarpal bone; APL, abductor pollicis longus.
The 4-5 radial periosteal flap can be used to treat scaphoid pseudoarthrosis, Kienböck disease and distal ulnar pseudoarthrosis. Due to its shorter pedicle length, it only allows the scaphoid or lunate to be approached dorsally. None of these flaps resulted in complications or sequelae at the donor area.

\section{Clinical Cases}

In a 38-year-old man with an avascular necrosis of the proximal scaphoid pole (D4) for 1 year, a first MTC periosteal flap was combined with an ipsilateral distal radius corticalcanellous bone graft (-Fig. 13). A dorsal approach was performed on the dorsum of the first MTC bone, dissecting the area between APL and EPB and identifying the vascular axis of the first dorsal metatarsal artery. The periosteal branches towards the first MTC bone were identified and the flap was designed in the most distal and dorsal area of the MTC bone (maximum, $1.2 \times 4 \mathrm{~cm}$ ). The flap and vascular pedicle were elevated after a subperiosteal dissection at the distal level, a proximal section of the periosteum and a supraperiosteal dissection up to the trapezius-metacarpal bone capsule. ${ }^{25}$ ( - Fig. 14) The flap was recovered from below the extensor pollicis brevis tendon because the scaphoid bone was approached from a volar position. Before applying the periosteal flap, the necrotic focus was screened, filled with an ipsilateral distal radius cortical-cancellous bone graft, and an antegrade fixation was performed with a cannulated compressive screw $(2.4 \mathrm{~mm})$. Finally, the periosteal flap was adapted perfectly to the size and shape of the receptor bed defect and stabilized with sutures. The total design time for flap dissection and elevation is inferior to

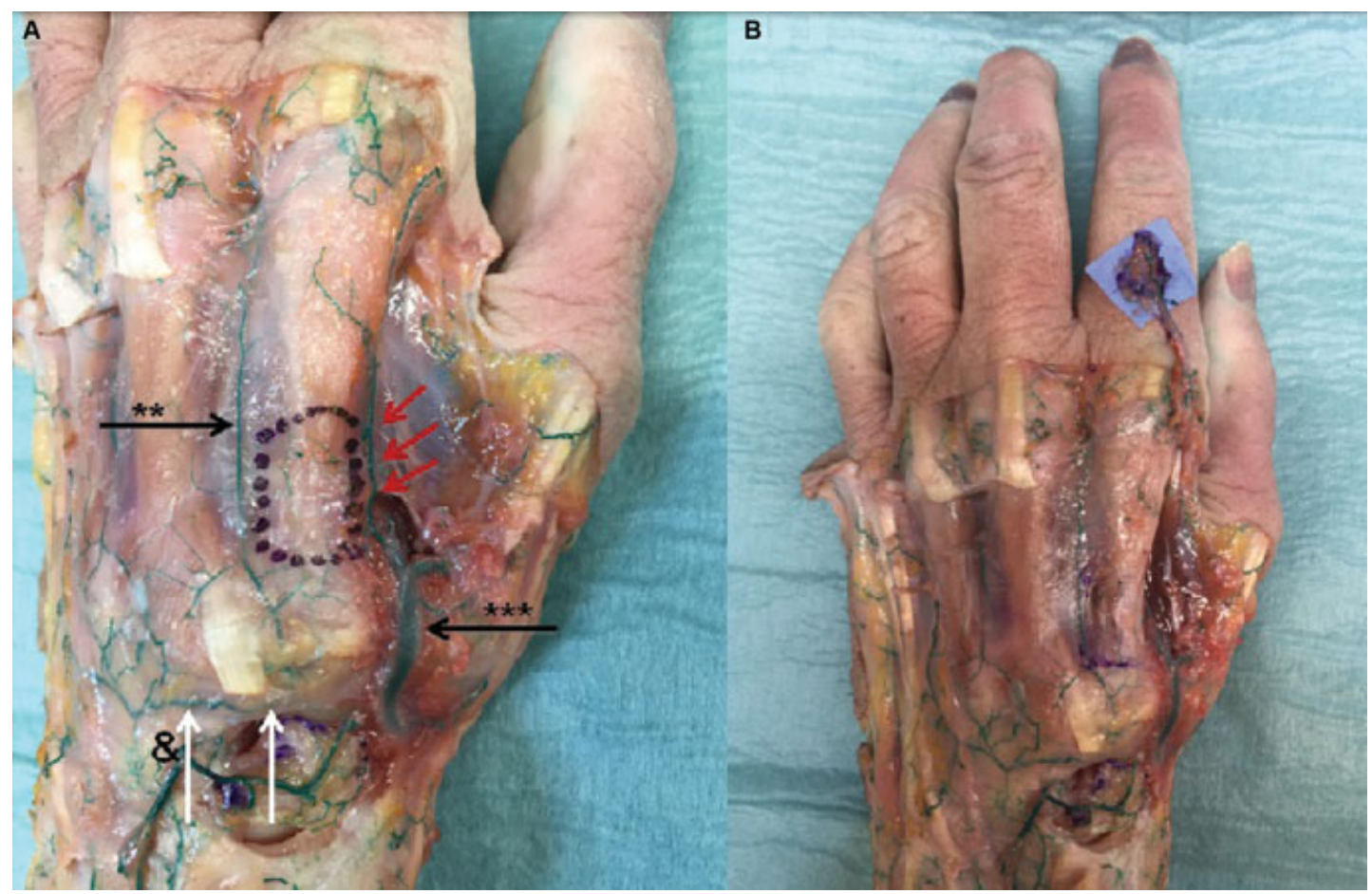

Fig. 11 Vascularized periosteal flap from the base of the second metacarpal bone. A, ${ }^{* * *}$, Dorsal branch of the radial artery; ${ }^{* *}$, second intermetacarpal branch; \&: dorsal carpal branch of the radial artery (white arrows), periosteal branches from the second intermetacarpal branch (red arrows). B, Vascularized periosteal flap elevation to its maximum extension at the proximal phalanx. 


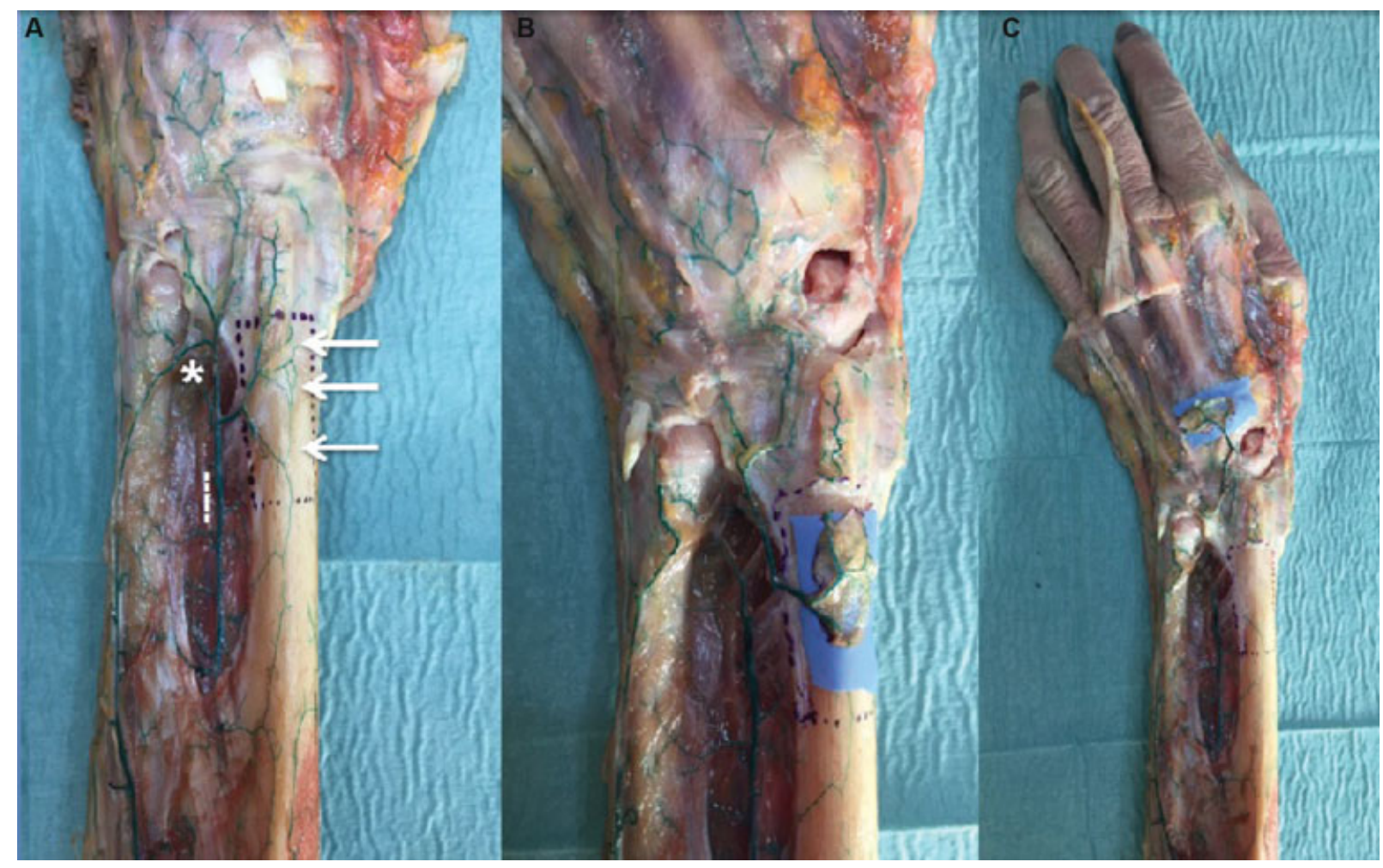

Fig. 12 Radial 4-5 vascularized periosteal flap design. A, Periosteal branches (arrows); *, anastomotic arch between the anterior interosseous artery and the posterior interosseous artery; -, dorsal branch of the anterior interosseous artery. B, Elevation of the periosteal branches-based flap. C, Length allowed by the pedicle up to the base of the $3^{\text {rd }}$ metacarpal bone.

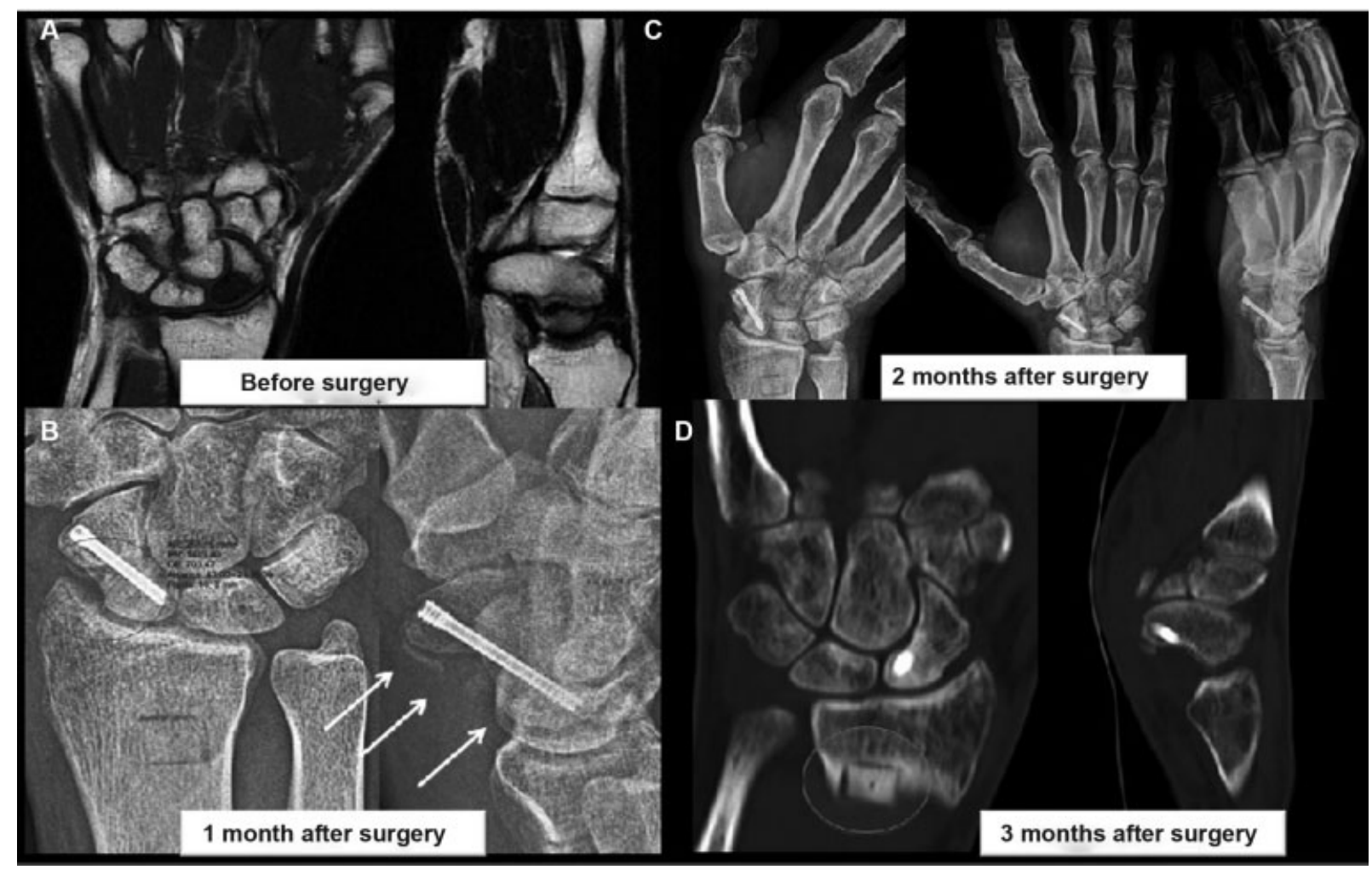

Fig. 13 Clinical case. A, Magnetic resonance imaging (MRI) of the right wrist from a 38-year-old male showing avascular necrosis of the proximal pole of the scaphoid for 1 year. B, Anteroposterior (AP) and lateral radiographies of the wrist, 1 month after surgery, showing a periosteal callus in the scaphoid (lateral image; arrows) and increased bone density. C, AP, lateral and Schneck radiographies of the wrist 2 months after surgery. D: Computed tomography (CT) scan of the wrist CT showing complete consolidation even faster compared to the cancellous graft donor area at the distal radius. 


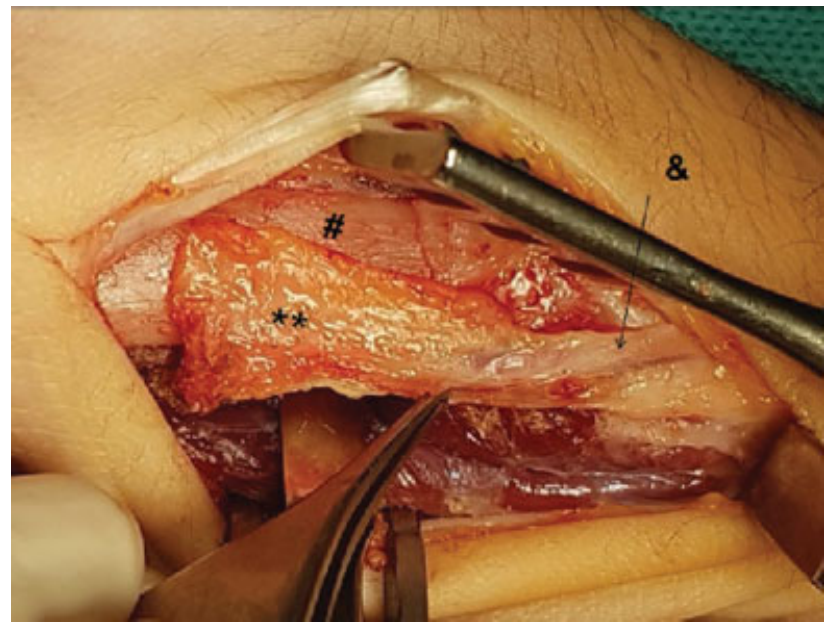

Fig. 14 Vascularized periosteal flap (VPF) from the dorsum of the first metacarpal $\left(1^{\text {st }}\right.$ MTC) bone; ${ }^{* *}$ : Pediculated VPF based on the periosteal branches of the first dorsal metacarpal artery. \#, $1^{\text {st }}$ metacarpal bone, \&, first dorsal metacarpal artery.

20 minutes. Initial consolidation signs were seen one month after surgery, and two months later, consolidation and revascularization were complete.

\section{Clinical Cases}

A pediculate VPF of the second MTC base was used to treat a pseudoarthrosis at the proximal phalanx of the third finger from a 12-year-old boy with coronal and sagittal deformity for 1.5 years. The deformity was corrected through an osteotomy and pseudoarthrosis focus debridement. Fixation used a retrograde compressive intramedullary screw $(2.0 \mathrm{~mm})$ and a periosteal flap (-Fig. 15).

A VPF from the second MTC bone is prepared through a centered dorsal approach on the base of the bone. The dorsal carpal branch of the radial artery is identified. The extensor indicis [proprius and communis] muscles are separated and the first dorsal intermetacarpal branch is identified. The periosteal branches are visualized on the basis of the second MTC bone. Since the defect to be treated is at a distal level, the flap is designed in a retrograde direction. Thus, the intermetacarpal branch is ligated proximally and the flap is elevated distally, preserving the periosteal vascularization in a retrograde direction through the volar branches of the palmar arch. The pedicle is dissected up to the subcapitate region, until the required length to cover the back of the proximal phalanx of the adjacent finger is achieved. Using sutures, the flap is applied to the defect. In this case, as this was a pediatric patient, no cortico-cancellous bone graft was added. At 5 weeks, radiological consolidation with deformity correction was achieved.

\section{Discussion}

This article described the anatomy, clinical applicability and some novel clinical cases on the use of VPF in common upper limb conditions. ${ }^{16-18,25}$ The new VPFs presented in this article are those of the dorsal wrist and hand (4-5 radial and dorsum of the second MTC bone).

Most VPFs have been previously described in some other format, including vascularized bone or fascio-cutaneous flaps, ${ }^{8,21}$ especially in adult patients. Therefore, the VPFs presented here must be considered modifications from the previous ones, elevating the periosteum alone.

VPFs provide certain advantages over vascularized bone flaps. Technically, they are easier to elevate because they do not require the meticulous work used in bone flaps for upper limb conditions. ${ }^{17,25}$ On the other hand, the periosteal tissue flexibility provides an easy and quick adaptability to the receptor bed, usually allowing a complete or partial coverage of the focus to be treated; moreover, the contact surface between the VPF and the receiving bed is increased, speeding up the whole biological process related to bone flaps. ${ }^{3,4,17}$

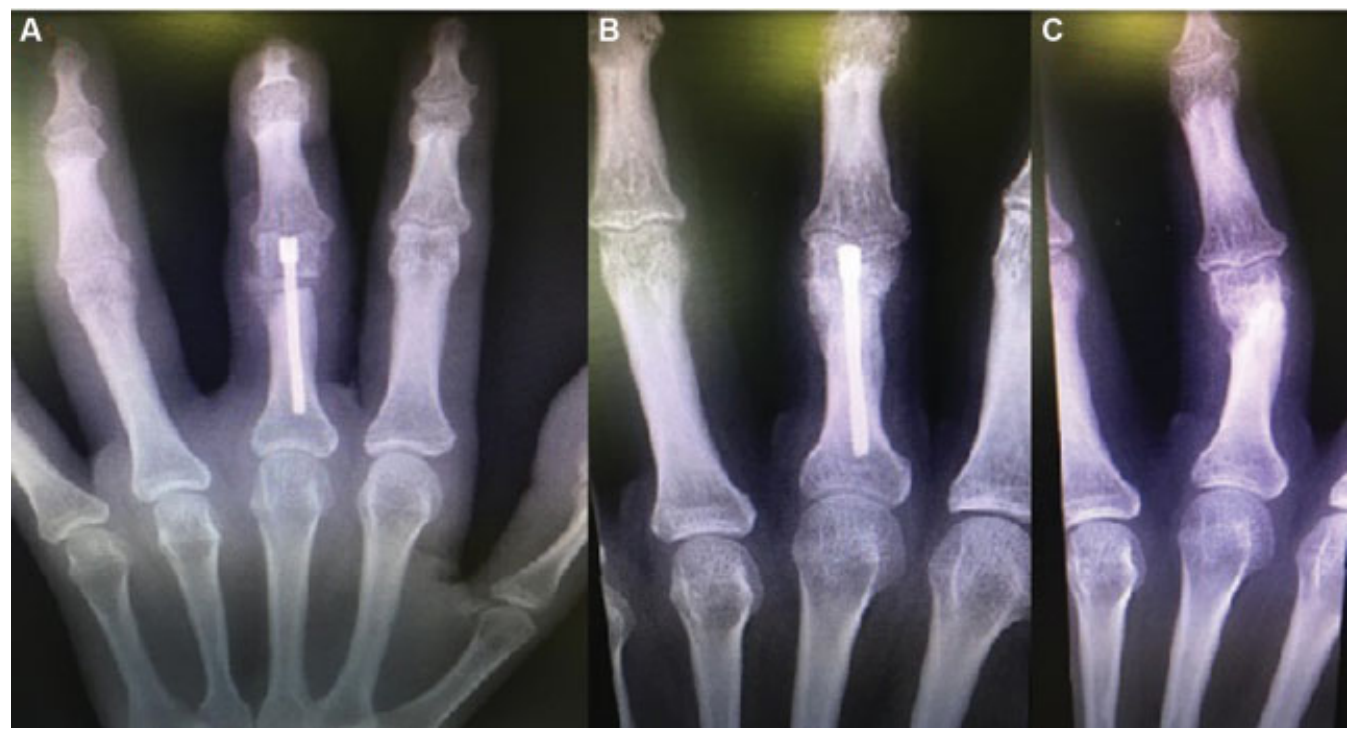

Fig. 15 Male, 12-year- male patient with a fracture first phalanx from the third finger. A, Pseudoarthrosis focus debridement, corrective osteotomy and fracture fixation. B and C, Complete fracture radiological consolidation. 
Another great advantage of VPFs is their versatility; most of them can be designed in an antegrade and retrograde way, ${ }^{19}$ in a simple or "chimera" format, providing a wide range of possibilities to treat conditions from the elbow to the phalanges. We prefer the humeral VPF for the treatment of CLH pseudoarthrosis ${ }^{18}$ and the dorso-ulnar VPF to address forearm conditions, from the olecranon to the wrist, including cases on the back of the hand with higher osteogenic requirement. In diaphyseal conditions, the VIA-based volarradial VPF is preferred, ${ }^{16}$ whereas the VPF of the back of the first MTC bone must be used in scaphoid pseudoarthrosis from either a volar or dorsal approach; ${ }^{17,25}$; the $4-5$ radial VPF is used to treat Kienböck disease and the VPF from the base of the second MTC bone is indicated in metacarpal and proximal phalange conditions.

VPFs have demonstrated their great osteogenic, osteoinductive, and osteoconductive strength in multiple previous publications, all in pediatric patients, ${ }^{3,4,17,18}$ but we reported several clinical cases in adults in which VPFs were also successful. This opens up a new possibility for the use of VPFs in adults, in which there were no previous cases reported in the literature.

\section{Conflict of Interests}

The authors have no conflict of interests.

\section{References}

1 Lewallen RP, Peterson HA. Nonunion of long bone fractures in children: a review of 30 cases. J Pediatr Orthop 1985;5(02):135-142

2 Soldado F, Fontecha CG, Barber I, et al. Vascularized fibular periosteal graft: a new technique to enhance bone union in children. J Pediatr Orthop 2012;32(03):308-313

3 Soldado F, Garcia Fontecha C, Haddad S, Hernandez-Fernandez A, Corona P, Guerra-Farfan E. Treatment of congenital pseudarthrosis of the tibia with vascularized fibular periosteal transplant. Microsurgery 2012;32(05):397-400

4 Soldado F, Knörr J, Haddad S, et al. Vascularized tibial periosteal graft in complex cases of bone nonunion in children. Microsurgery 2015;35(03):239-243

5 Soldado F, Barrera-Ochoa S, Fontecha CG, et al. Vascularized periosteal graft from the first metatarsal bone: a new technique to prevent collapse of osteonecrosis of the talus in children. A case report. Microsurgery 2013;33(01):56-59

6 Alman BA, De Bari A, Krajbich JI. Massive allografts in the treatment of osteosarcoma and Ewing sarcoma in children and adolescents. J Bone Joint Surg Am 1995;77(01):54-64

7 Masquelet AC, Begue T. The concept of induced membrane for reconstruction of long bone defects. Orthop Clin North Am 2010; 41(01):27-37

8 Cavadas PC, Landín L. Treatment of recalcitrant distal tibial nonunion using the descending genicular corticoperiosteal free flap. J Trauma 2008;64(01):144-150
9 Sakai K, Doi K, Kawai S. Free vascularized thin corticoperiosteal graft. Plast Reconstr Surg 1991;87(02):290-298

10 CrockJG, Morrison WA. A vascularised periosteal flap: anatomical study. Br J Plast Surg 1992;45(06):474-478

11 Vegas MR, Delgado P, Roger I, Carosini R. Vascularized periosteal transfer from the medial femoral condyle: is it compulsory to include the cortical bone? J Trauma Acute Care Surg 2012;72(04): 1040-1045

12 Diaz-Gallardo P, Knörr J, Vega-Encina I, et al. Free vascularized tibial periosteal graft with monitoring skin island for limb reconstruction: Anatomical study and case report. Microsurgery 2017; 37(03):248-251

13 Qi B, Yu A, Zhang G, et al. The treatment of displaced femoral neck fractures with vascularized great trochanter periosteal flap transposition in children. Microsurgery 2008;28(01):21-24

14 Gallardo-Calero I, Barrera-Ochoa S, Manzanares MC, et al. Vascularized Periosteal Flaps Accelerate Osteointegration and Revascularization of Allografts in Rats. Clin Orthop Relat Res 2019;477 (04):741-755

15 Flynn JC. Nonunion of slightly displaced fractures of the lateral humeral condyle in children: an update. J Pediatr Orthop 1989;9 (06):691-696

16 Barrera-Ochoa S, Campillo- Recio D, Knörr J, Mir-Bullo X, Soldado F, Rodriguez-Baeza A. Anatomical study of periosteal vascularization of the forearm: Design of vascularized periosteal flap. Rev Iberoam Cir Mano. 2018;46:106-112

17 Barrera-Ochoa S, Mendez-Sanchez G, Mir-Bullo X, Knörr J, Bertelli JA, Soldado F. Vascularized Thumb Metacarpal Periosteal Flap for Scaphoid Nonunion in Adolescents: A Prospective Cohort Study of 12 Patients. J Hand Surg Am 2019;44(06):521.e1-521.e11

18 Barrera-Ochoa SS, Soldado F, Rodriguez-Baeza A, et al. Vascularized humeral periosteal flap to treat lateral humeral condyle nonunion: An anatomical study and report of two successfullytreated pediatric cases. Microsurgery 2019;39(02):156-159

19 Barrera-Ochoa S, Velez R, Rodriguez-Baeza A, De Bergua-Domingo JM, Knörr J, Soldado F. Vascularized ulnar periosteal pedicled flap for forearm reconstruction: Anatomical study and a case report. Microsurgery 2018;38(05):530-535

20 Pagnotta A, Taglieri E, Molayem I, Sadun R. Posterior interosseous artery distal radius graft for ulnar nonunion treatment. J Hand Surg Am 2012;37(12):2605-2610

21 Kamrani RS, Mehrpour SR, Sorbi R, Aghamirsalim M, Farhadi L. Treatment of nonunion of the forearm bones with posterior interosseous bone flap. J Orthop Sci 2013;18(04):563-568

22 Akin S, Ozgenel Y, Ozcan M. Osteocutaneous posterior interosseous flap for reconstruction of the metacarpal bone and soft-tissue defects in the hand. Plast Reconstr Surg 2002;109(03):982-987

23 Park H, Hwang JH, Kwon YU, Kim HW. Osteosynthesis in situ for lateral condyle nonunion in children. J Pediatr Orthop 2015;35 (04):334-340

24 Kloen P, Buijze GA, Ring D. Management of forearm nonunions: current concepts. Strateg Trauma Limb Reconstr 2012;7(01): $1-11$

25 Barrera-Ochoa S, Mendez-Sanchez G, Rodriguez-Baeza A, Knörr J, Bertelli JA, Soldado F. Vascularized thumb metacarpal periosteal pedicled flap for scaphoid nonunion: An anatomical study and pediatric case report. Microsurgery 2019;39(01):62-69 